\title{
Response of Foliar Feeding of Gluconate and EDTA Chelated Plant Nutrients on Growth, Yield and Absorption of Nutrients by Leaves in Bt-Cotton under Rainfed Condition
}

\author{
P.H. Gourkhede, V.D. Patil and D.T. Pathrikar* \\ Department of Soil Science and Agril Chemistry VNMKV, Parbhani-431402 (MS), India \\ *Corresponding author
}

\section{Keywords \\ Chelated plant nutrients, Absorption, Nutrients, Foliar feeding, Gluconate, EDTA, Yield, Bt cotton \\ Article Info \\ Accepted: \\ 10 March 2019 \\ Available Online: \\ 10 April 2019}

\section{A B S T R A C T}

An experiment was conducted during 2010-11 to find out the "Response of foliar feeding of Gluconate and EDTA chelated plant nutrients on growth, yield and absorption of nutrients by leaves in Bt-cotton under rainfed condition" at Department of Soil Science and Agril Chemistry, VNMKV, Parbhani. The experiment includes seventeen treatment includes viz., $\mathrm{T}_{1}-\mathrm{Zn}$ Gluconate, $\mathrm{T}_{2}-\mathrm{Mn}$ Gluconate, $\mathrm{T}_{3}-\mathrm{Cu}$ gluconate, $\mathrm{T}_{4^{-}}$Fe Gluconate, $\mathrm{T}_{5^{-}}$ Ca Gluconate, $T_{6}-$ Mg Gluconate, $T_{7}$ - combination of all Gluconate, $T_{8}-Z n-E D T A, T_{9}-M n$ EDTA, $\mathrm{T}_{10^{-}}$Cu EDTA, $\mathrm{T}_{11^{-}}$-Fe EDTA, $\mathrm{T}_{12}-$ Ca EDTA, $\mathrm{T}_{13^{-}}$Mg EDTA, $\mathrm{T}_{14^{-}}$combination of all EDTA, $\mathrm{T}_{15^{-}}$Govt. grade II, $\mathrm{T}_{16^{-}}$Water spray and $\mathrm{T}_{17^{-}}$Control replicated twice. The treatments were fertilized with 120:60:60 N, $\mathrm{P}_{2} \mathrm{O}_{5}$ and $\mathrm{K}_{2} \mathrm{O} \mathrm{Kg}$ ha ${ }^{-1}$. Foliar spray of gluconate and EDTA chelated nutrients were given at 75 DAS. Biometric observations such as height of plant, number of leaves, leaf area and yield attributes such as number of bolls per plant, weight of boll and yield were taken at 80,100 and 120 DAS. Immediately after $3,6,12,24,36$ and 48 hours of sprays nutrient concentration was determined by adopting suitable method. Five leaves from each treated plants were collected to find out the absorption time of plant nutrients. The result revealed that foliar feeding of $\mathrm{Zn}$ gluconate showed maximum growth and yield. The foliar feeding of $\mathrm{Zn}$ through $\mathrm{Zn}$ Gluconate had maximum absorption and it was between 3-6 hours. Iron concentration was more after 6 hours due to application of Fe Gluconate, followed by Fe EDTA as compaired to control. While the application of manganese Gluconate showed maximum absorption of manganese by $\mathrm{Bt}$. Cotton plant. Further application of $\mathrm{Cu}$ Gluconate recorded more absorption of $\mathrm{Cu}$ after 6 hours of spray over control, water spray and Government grade II.

\section{Introduction}

Cotton (Gosspium spp.) is one of the most important commercial crops playing a key role in economical, political and social status of the world and so has retained its unique fame and name as the "King of fibres" and
"White gold" because of its higher economical value among cultivable crops for quite a long period. It was the superiority of Indian cotton fabrics famed as "Web of woven mind" which attracted European countries to seek new trade routes to India. Indian economy continued to receive great 
support from the cotton industry, is one of the major industries in India contributing 12 per cent to the export basket with improved cotton productivity and other innovations. In the production line, India will be in a position to get more foreign exchange and earned Rs. 10270.21 crores from export of 83.00 lakh bales in 2009-10 (Cotton Advisory Board).

The nutrient supply is the second most important limiting factor in cotton production only after water. Most often soils in the rainfed area are not only thirsty but also hungry for the nutrients. Basically, soils sickness vis-a-vis nutritional stress is the result of deficiency of macro and micronutrients in soil. Deficiency, disorder and demand are internally related with each other in balanced plant diet. Macronutrient deficiency in soil is one of the major causes for yield reduction for wide array of crops. Continuous cropping of high yielding varieties without proper substitution of inorganic fertilizers, non-addition of micronutrients, and less or no application of organic manures have caused excessive removal of essential nutrients from the soil reserves that eventually led to the deficiency of micronutrients in soils. There is an urgent need to target the problem correctly mid specifically for precise fertilizer prescription. Hence, for significant improvement in production and productivity of cotton, these constraints, in fact need to be managed with top priority in the research agenda. In other wards cotton productivity can be improved significantly by efficient management of nutrients through an integrated approach. Taking into consideration, the capacity and benefit of $\mathrm{Bt}$ cotton in terms of yield and quality, the nutritional requirement of $\mathrm{Bt}$ cotton could be maintained by applying the deficient nutrient through soil application and foliar spray. Lack of adequate knowledge about the required amount, kind of fertilizer and method of application to a field for a particular crop also results in deficiency or excessive fertilizer application causing imbalance among nutrients so the balanced nutrient fertilizer use is a perquisite for sustaining high yield. Plant nutrition have traditionally considered the obvious way to feed plants is through the soil, where plant roots are meant to uptake water and nutrients but in recent years foliar feeding has been developed to supply plants with their nutritional needs. Foliar feeding is the application or feeding of a plant, a liquid plant nutrient or nutrient additive through the leaves instead of via the root. It is a method of plant fertilization which involves applying fertilizer directly to the leaves in the form of solution which is spread on the tiny pores in the leaves allows the fertilizer to pass into the plant providing needed nutrition. Foliar nutrients are mobilized directly into plant leaves which are the goal of fertilization to begin with increasing the rate of photosynthesis in the leaves and by doing so stimulate nutrient absorption by plant roots. When the foliar plant food is sprayed on the leaves, it causes the plant metabolism to speed up. This causes the plant to demand more water and nutrients from the root system. It is this increase in water and nutrient sent by the roots that provides the potential for higher yield. It is one of the ways to replenish the required nutrient in critical growth stages and is a rapid and effective method of supplying the micronutrients. These micronutrients could be supplied through EDTA (Ethylendiamine Tetra Acetic Acid) which has property of forming stable soluble complexes with certain monovalent, divalent and trivalent metal ions. The chelates in which the chemical compounds are firmly combined with a molecule by means of multiple chemical bond. Chelation is the process of attaching a specific organic molecule called a "ligand" to mineral ion at two or more sites to form a ring structure. Chelates can either by synthetic or natural. 
So, the foliar application assumes greater importance, as the nutrients are brought in the immediate vicinity of the metabolizing area i.e. foliage.

\section{Materials and Methods}

A potted experiment was conducted in the kharif season of 2010-11 at the Department of Soil Science and Agril. Chemistry, MKV, Parbhani. The large cement pots of $12 \mathrm{~kg}$ capacity were utilized for experiment. The treatment symbols were marked with paint. The air dried and clean soil was passed through a $2 \mathrm{~mm}$ nylon screen. For the pot culture experiment 20 pots were taken to study the absorption of Gluconate and EDTA chelated micronutrient through foliar feeding. The treatments included foliar sprays of $\mathrm{Zn}$, $\mathrm{Mn}, \mathrm{Cu}, \mathrm{Fe}, \mathrm{Ca}, \mathrm{Mg}$ gluconate, all gluconate, and also through $\mathrm{Zn}, \mathrm{Mn}, \mathrm{Cu}, \mathrm{Fe}, \mathrm{Ca}, \mathrm{Mg}$ EDTA, all EDTA, straight fertilizer government grade spray, water spray and control. The sowing of seed was done on $2^{\text {nd }}$ July, 2010. Two seeds per pot of variety $\mathrm{RCH}-2$ (BG-II) were placed in each pot and watered regularly as and when necessary. The pots were fertilized at the rate of 120:60:60 kg NPK ha ${ }^{-1}$ through urea, single super phosphate and muriate of potash respectively. Foliar spray of gluconate and EDTA chelated was given at 75 DAS. Biometric observation such as viz., height of plant, number of leaves, leaf area, number of boll, weight each of bolls and yield were taken at 80,100 and 120 DAS. Immediately after spray of nutrients observations were taken after 3, 6, 12, 24, 36 and 48 hours. Five leaves from each treated pot were collected to find out the absorption of plant nutrients through various treatments. The data emerged out from the field experiment were analysed by analysis of variance and degree of freedom were partitioned into different variance, due to replication and treatments combinations. These were compared with error variance for finding out ' $F$ ' value and ultimately for testing the significance. The standard error (SE) for the treatment was calculated based on error variance when ever, the results were found to be significant, critical difference (CD) were calculated for comparison of treatment means at 5 per cent level of significance. Results were statistically analysed as per the method given in statistical method for agricultural workers by Panse and Sukhatme (1987).

\section{Results and Discussion}

\section{Height of plant}

After taking the spray of chelated nutrients the observation on height was recorded at 100 and 120 DAS. At 100 and 120 DAS the height of Bt cotton crop ranged from 24.23 to 57.41 and 31.52 to $65.55 \mathrm{~cm}$, respectively. The effective treatment for increasing the height of the $\mathrm{Bt}$ cotton crop was zinc gluconate $\left(\mathrm{T}_{4}\right)$ i.e. 57.41 and $65.55 \mathrm{~cm}$, respectively. Same treatments like $\mathrm{T}_{5}(\mathrm{Zn}$ EDTA), $\mathrm{T}_{10}$ (Fe gluconate) and $\mathrm{T}_{11}$ (Fe EDTA) closely followed the treatment $\mathrm{T}_{4}(\mathrm{Zn}$ gluconate).

\section{Number of leaves}

Table 1 showed the highest number of leaves were recorded with treatment $\mathrm{T}_{4}$ i.e. zinc gluconate spray as 105.50 and 121.00 at 100 and at 120 DAS, respectively. Whereas, the lowest was recorded as 43.50, 59.25 and 66.50 leaves in treatment $\mathrm{T}_{1}$ (control), respectively.

\section{Leaf area}

Maximum leaf area was recorded with the application of zinc gluconate (2562 and 3093 $\mathrm{cm}^{2}$ ). Whereas the lowest leaf area was observed with treatment $\mathrm{T}_{1}$ (control) (1136.09 and $1401.72 \mathrm{~cm}^{2}$ ) at 100 and 120 DAS, 
respectively. The results are in agreement with Sarkar and Aery (1990) they reported that application of $\mathrm{Zn}$ to pot trial had effect an increased leaf area of Bt cotton crop.

\section{Dry weight}

This table 2 revealed that the dry weight of $\mathrm{Bt}$ cotton crop after harvest was recorded. These records revealed that the dry weight was to the tune 61.69 in control and $104.74 \mathrm{~g} \mathrm{plant}^{-1}$ in $\mathrm{Zn}$ gluconate spray. The treatment $\mathrm{T}_{4}(\mathrm{Zn}$ gluconate) recorded significant increase in the dry matter of Bt cotton plants.

\section{Yield parameters}

Effect of one foliar feeding of gluconate and EDTA chelated plant nutrient after 80 DAS on following yield parameters are presented in Table 2.

\section{Yield}

Application of zinc gluconate had significant effect in improving the number of bolls plant 1 . The highest of 39 bolls plant $^{-1}$ were recorded against the lowest treatment $T_{1}$ (control) i.e. 11 bolls plant ${ }^{-1}$. Weight of bolls were ranged from 2.08 to $3.43 \mathrm{~g}$. The heavier weight of per boll was observed due to application of $\mathrm{T}_{4}$ (zinc gluconate) (3.43 g) foliar spray to Bt cotton crop. The lowest was noted in treatment $\mathrm{T}_{1}$ (control) $(2.08 \mathrm{~g}$ ). The result revealed that yield per plant was maximum with application of zinc gluconate $(133.77 \mathrm{~g})$ followed by the treatment like $\mathrm{T}_{10}$ (Fe gluconate) (116.64 g) and $\mathrm{T}_{5}$ (Zn EDTA) (115.6 g).

\section{Effect of foliar feeding of gluconate and EDTA chelated plant nutrient on concentration of plant nutrients in leaves}

Immediately after spray, observation were taken after 3, 6, 12, 24, 36 and 48 hours. The data pertaining to respective nutrients are presented in Table 3-8.

\section{Ca concentration}

Observations at various hours intervals revealed that the treatment $\mathrm{T}_{4}$ (Cagluconate) shows increasing trend of $\mathrm{Ca}$ concentration by Bt cotton plants.

As the time progressed, the rate of absorption was also increasing till 48 hours. Here, it could be specially noted that the rate of absorption of $\mathrm{Ca}$ was highest between the 3 to 6 hours comparing with other time intervals and thereafter, its rate slowed done up to 48 hours. Among all the treatment $\mathrm{T}_{4}$ (Cagluconate) recorded highest $\mathrm{Ca}$ absorption followed by $\mathrm{T}_{5}$ (Ca EDTA) and lowest in $\mathrm{T}_{1}$ (control).

\section{Mg concentration}

Application of $\mathrm{Mg}$ gluconate $\left(\mathrm{T}_{4}\right)$ resulted highest concentration of $\mathrm{Mg}$ by $\mathrm{Bt}$ cotton plants.

It was keenly observed that maximum absorption was noted between the time intervals 3 to 6 hours. Treatment $\mathrm{T}_{5}(\mathrm{Mg}$ EDTA) also followed closely with $\mathrm{T}_{4}(\mathrm{Mg}$ gluconate). The maximum absorption was between 6-12 hours. Same role of absorption was noted with the $\mathrm{T}_{3}$ (Government grade 2 ).

\section{Zn concentration}

Foliar feeding of zinc gluconate $\left(\mathrm{T}_{4}\right)$ was superior in its effect of over the absorption of zinc by the Bt cotton against the $\mathrm{T}_{1}$ (control) and $\mathrm{T}_{2}$ (water spray). The treatment $\mathrm{T}_{1}$ and $\mathrm{T}_{2}$ noticed very little change in zinc absorption.

Whereas, absorption by treatment $T_{3}$ (Government grade 2) had better absorption at 6-12 hours, whereas the amount and rate of absorption of zinc was highest during the 3-6 hours in gluconate complexed $\mathrm{Zn}$ salt followed by $\mathrm{T}_{5}$ (Zn EDTA). 
Das et al., (2004) suggested that the use of efficient of applied $\mathrm{Zn}$ in the form of $\mathrm{Zn}$ EDTA has been proved always higher in relation to $\mathrm{Zn}$ content in soil and plants reflecting higher increase in yield as compared to $\mathrm{Zn}$ application as $\mathrm{ZnSO}_{4}$. Jat and Mehra (2007) stated that the favourable influence of zinc on photosynthesis and metabolic processes augments the production of photosynthesis and their translocation to different plant parts including grain. $\mathrm{z}$

\section{Fe concentration}

The iron concentration average mean ranged from 30.60 to $34.91 \mathrm{mg} \mathrm{kg}^{-1}$ are presented.

The rate and maximum absorption was noticed with the treatment $\mathrm{T}_{4}$ (Fe gluconate) (i.e. from 36.24 to 43.79) followed numerically closed by $\mathrm{T}_{5}$ (Fe EDTA) (i.e. from 35.77 to 40.15$)$ and lowest range was recorded with $\mathrm{T}_{1}$ (control) (i.e. from 23.43 to 23.50) and $\mathrm{T}_{2}$ (water spray) (i.e. from 27.01 to 28.01). The rate of absorption of iron was higher at time interval of 3-6 hours in case of $\mathrm{T}_{4}$ (Fe gluconate) treatment.

Gangadhar et al., (1992) noted the application of $\mathrm{FeSO}_{4}$ increased significantly the content of $\mathrm{Fe}, \mathrm{Zn}, \mathrm{Mn}, \mathrm{Cu}$ and $\mathrm{B}$ nutrients in the index leaf $\left(4^{\text {th }}\right.$ leaf) and uptake of nutrients by the crop.

\section{Mn concentration}

The data in Table 7 revealed that absorption of nutrient was increased, due to foliar application of same nutrient. Here also $\mathrm{T}_{4}$ (Mn gluconate) spray helped for absorption of manganese by Bt cotton plants than all other treatments.

Table.1 Effect of foliar feeding of gluconate and EDTA chelated plant nutrient on height of plant, number of leaves and leaf area of Bt cotton in pot culture experiment

\begin{tabular}{|c|c|c|c|c|c|c|}
\hline \multirow[t]{2}{*}{ Treatment } & \multicolumn{2}{|c|}{ Height of plant (cm) } & \multicolumn{2}{|c|}{ Number of leaves } & \multicolumn{2}{|c|}{ Leaf area $\left(\mathrm{cm}^{2}\right)$} \\
\hline & 100 DAS & 120 DAS & 100 DAS & 120 DAS & 100 DAS & 120 DAS \\
\hline $\mathbf{T}_{1}$-Control & 24.23 & 31.52 & 59.25 & 66.50 & 1136.09 & 1401.72 \\
\hline$T_{2}$-Water spray & 29.01 & 37.40 & 64.75 & 73.25 & 1308.27 & 1620.44 \\
\hline$T_{3}$-Government grade 2 & 39.28 & 51.37 & 76.25 & 90.25 & 1810.09 & 2250.13 \\
\hline $\mathbf{T}_{4}-\mathrm{Zn}$ gluconate & 57.41 & 65.55 & 105.50 & 121.00 & 2562.82 & 3093.06 \\
\hline$T_{5}-Z n$ EDTA & 56.78 & 64.79 & 103.00 & 119.75 & 2501.85 & 3001.75 \\
\hline $\mathrm{T}_{6}-\mathrm{Mn}$ gluconate & 43.75 & 53.10 & 84.75 & 101.25 & 1957.69 & 2498.55 \\
\hline$T_{7}$-Mn EDTA & 42.21 & 53.00 & 83.50 & 97.50 & 1923.47 & 2418.24 \\
\hline $\mathrm{T}_{\mathbf{8}^{-}} \mathrm{Cu}$ gluconate & 38.36 & 46.25 & 75.50 & 86.00 & 1663.45 & 2132.73 \\
\hline$T_{9}-\mathrm{Cu}$ EDTA & 37.15 & 45.76 & 74.00 & 84.75 & 1559.01 & 2109.12 \\
\hline $\mathrm{T}_{10}$-Fe gluconate & 52.98 & 61.80 & 99.50 & 115.25 & 2373.18 & 2849.71 \\
\hline$T_{11}$-Fe EDTA & 52.08 & 61.59 & 97.50 & 112.50 & 2298.75 & 2782.90 \\
\hline $\mathrm{T}_{12}$-Ca gluconate & 33.87 & 42.09 & 70.50 & 80.00 & 1500.67 & 2099.65 \\
\hline$T_{13}$-Ca EDTA & 33.69 & 41.88 & 68.75 & 78.75 & 1478.82 & 1901.14 \\
\hline $\mathrm{T}_{14}-\mathrm{Mg}$ gluconate & 48.72 & 57.77 & 92.50 & 108.50 & 2087.64 & 2615.21 \\
\hline$T_{15}-M g$ EDTA & 48.19 & 57.63 & 90.25 & 105.00 & 2009.50 & 2673.64 \\
\hline Mean & 42.51 & 51.43 & 83.03 & 96.01 & 1878.08 & 2363.19 \\
\hline
\end{tabular}


Table.2 Effect of foliar feeding of gluconate and EDTA chelated plant nutrient on fresh weight, dry weight, number of bolls, weight of bolls and weight of bolls $g$ plant ${ }^{-1}$ of Bt cotton in pot culture experiment

\begin{tabular}{|c|c|c|c|c|}
\hline Treatment & $\begin{array}{l}\text { Dry weight } \\
\left(\text { g palnt }^{-1}\right)\end{array}$ & $\begin{array}{c}\text { Number of bolls } \\
\text { plant }^{-1}\end{array}$ & $\begin{array}{l}\text { Weight of boll } \\
\text { (g) }\end{array}$ & Yield $\left(\right.$ g plant $\left.^{-1}\right)$ \\
\hline$T_{1}$-Control & 61.69 & 11 & 2.08 & 22.88 \\
\hline$T_{2}$-Water spray & 65.39 & 15 & 2.30 & 34.50 \\
\hline $\mathrm{T}_{3}$-Government grade 2 & 80.02 & 23 & 2.96 & 68.08 \\
\hline $\mathbf{T}_{4}-\mathrm{Zn}$ gluconate & 104.74 & 39 & 3.43 & 133.77 \\
\hline$T_{5}-\mathrm{Zn}$ EDTA & 102.97 & 34 & 3.40 & 115.60 \\
\hline $\mathbf{T}_{6}-\mathrm{Mn}$ gluconate & 186.25 & 27 & 3.06 & 82.62 \\
\hline $\mathbf{T}_{7}-\mathbf{M n}$ EDTA & 85.73 & 26 & 3.03 & 78.78 \\
\hline $\mathrm{T}_{8}-\mathrm{Cu}$ gluconate & 78.34 & 23 & 2.90 & 66.70 \\
\hline $\mathrm{T}_{9}-\mathrm{Cu}$ EDTA & 76.85 & 20 & 2.82 & 56.40 \\
\hline$T_{10}$-Fe gluconate & 99.15 & 36 & 3.24 & 116.64 \\
\hline$T_{11}$-Fe EDTA & 99.01 & 30 & 3.21 & 96.30 \\
\hline$T_{12}$-Ca gluconate & 69.11 & 18 & 2.69 & 48.42 \\
\hline$T_{13}$-Ca EDTA & 68.39 & 16 & 2.63 & 42.08 \\
\hline$T_{14^{-}}$Mg gluconate & 95.61 & 31 & 3.12 & 96.72 \\
\hline$T_{15^{-}}$Mg EDTA & 94.82 & 30 & 3.10 & 93.00 \\
\hline Mean & 90.10 & 25.26 & 2.93 & 76.83 \\
\hline
\end{tabular}

Table.3 Effect of foliar feeding of gluconate and EDTA chelated plant nutrient on Ca concentration of Bt cotton in pot culture experiment

\begin{tabular}{|l|c|c|c|c|c|c|}
\hline \multirow{2}{*}{ Treatment } & \multicolumn{7}{|c|}{ Ca concentration } \\
\cline { 2 - 7 } & $\mathbf{3}$ hrs. & $\mathbf{6}$ hrs. & $\mathbf{1 2}$ hrs. & $\mathbf{2 4}$ hrs. & $\mathbf{3 6}$ hrs. & $\mathbf{4 8}$ hrs. \\
\hline $\mathbf{T}_{\mathbf{1}}$-Control & 0.32 & 0.32 & 0.32 & 0.32 & 0.33 & 0.33 \\
\hline $\mathbf{T}_{\mathbf{2}}$-Water spray & 0.33 & 0.30 & 0.34 & 0.38 & 0.38 & 0.38 \\
\hline $\mathbf{T}_{\mathbf{3}}$-Governemnt grade $\mathbf{2}$ & 0.43 & 0.43 & 0.48 & 0.49 & 0.51 & 0.53 \\
\hline $\mathbf{T}_{\mathbf{4}}$-CaGluconate & 0.69 & 0.78 & 0.79 & 0.81 & 0.83 & 0.85 \\
\hline $\mathbf{T}_{\mathbf{5}}$-Ca EDTA & 0.60 & 0.65 & 0.66 & 0.67 & 0.69 & 0.71 \\
\hline Mean & $\mathbf{0 . 4 7}$ & $\mathbf{0 . 5 0}$ & $\mathbf{0 . 5 2}$ & $\mathbf{0 . 5 3}$ & $\mathbf{0 . 5 5}$ & $\mathbf{0 . 5 6}$ \\
\hline
\end{tabular}

Table.4 Effect of foliar feeding of gluconate and EDTA chelated plant nutrient on $\mathrm{Mg}$ concentration of Bt cotton in pot culture experiment

\begin{tabular}{|l|c|c|c|c|c|c|}
\hline \multirow{2}{*}{ Treatment } & \multicolumn{7}{|c|}{ Mg concentration } \\
\cline { 2 - 7 } & $\mathbf{3}$ hrs. & $\mathbf{6}$ hrs. & $\mathbf{1 2}$ hrs. & $\mathbf{2 4}$ hrs. & $\mathbf{3 6}$ hrs. & $\mathbf{4 8}$ hrs. \\
\hline $\mathbf{T}_{\mathbf{1}}$-Control & 0.26 & 0.26 & 0.27 & 0.27 & 0.27 & 0.28 \\
\hline $\mathbf{T}_{\mathbf{2}}$-Water spray & 0.28 & 0.28 & 0.30 & 0.31 & 0.31 & 0.32 \\
\hline $\mathbf{T}_{\mathbf{3}}$-Governemnt grade 2 & 0.33 & 0.33 & 0.37 & 0.38 & 0.39 & 0.41 \\
\hline $\mathbf{T}_{\mathbf{4}}$-Mg Gluconate & 0.45 & 0.53 & 0.55 & 0.56 & 0.58 & 0.59 \\
\hline $\mathbf{T}_{\mathbf{5}}$-Mg EDTA & 0.42 & 0.49 & 0.50 & 0.51 & 0.52 & 0.53 \\
\hline Mean & $\mathbf{0 . 3 5}$ & $\mathbf{0 . 3 8}$ & $\mathbf{0 . 4 0}$ & $\mathbf{0 . 4 1}$ & $\mathbf{0 . 4 1}$ & $\mathbf{0 . 4 3}$ \\
\hline
\end{tabular}


Table.5 Effect of foliar feeding of gluconate and EDTA chelated plant nutrient on Zn concentration of Bt cotton in pot culture experiment

\begin{tabular}{|l|c|c|c|c|c|c|}
\hline \multirow{2}{*}{ Treatment } & \multicolumn{7}{|c|}{ Zn concentration } \\
\cline { 2 - 7 } & $\mathbf{3 ~ h r s .}$ & $\mathbf{6}$ hrs. & $\mathbf{1 2}$ hrs. & $\mathbf{2 4}$ hrs. & $\mathbf{3 6}$ hrs. & $\mathbf{4 8}$ hrs. \\
\hline T $_{\mathbf{1}}$-Control & 17.52 & 17.52 & 17.53 & 17.53 & 17.55 & 17.55 \\
\hline $\mathbf{T}_{\mathbf{2}}$-Water spray & 20.84 & 20.34 & 20.35 & 20.37 & 21.17 & 21.20 \\
\hline $\mathbf{T}_{\mathbf{3}}$-Governemnt grade $\mathbf{2}$ & 24.11 & 24.22 & 26.74 & 26.78 & 26.80 & 27.90 \\
\hline $\mathbf{T}_{\mathbf{4}}$-Zn Gluconate & 28.63 & 36.15 & 37.23 & 39.09 & 40.35 & 40.44 \\
\hline $\mathbf{T}_{\mathbf{5}}$ Zn EDTA & 28.04 & 35.42 & 35.79 & 36.18 & 36.29 & 36.65 \\
\hline Mean & $\mathbf{2 3 . 8 3}$ & $\mathbf{2 6 . 7 3}$ & $\mathbf{2 7 . 5 3}$ & $\mathbf{2 7 . 9 9}$ & $\mathbf{2 8 . 4 3}$ & $\mathbf{2 8 . 7 5}$ \\
\hline
\end{tabular}

Table.6 Effect of foliar feeding of gluconate and EDTA chelated plant nutrient on Fe concentration of Bt cotton in pot culture experiment

\begin{tabular}{|l|c|c|c|c|c|c|}
\hline \multirow{2}{*}{ Treatment } & \multicolumn{7}{|c|}{ Fe concentration } \\
\cline { 2 - 7 } & $\mathbf{3}$ hrs. & $\mathbf{6}$ hrs. & $\mathbf{1 2}$ hrs. & $\mathbf{2 4}$ hrs. & $\mathbf{3 6}$ hrs. & $\mathbf{4 8}$ hrs. \\
\hline $\mathbf{T}_{\mathbf{1}}$-Control & 23.43 & 23.44 & 23.46 & 23.46 & 23.47 & 23.50 \\
\hline $\mathbf{T}_{\mathbf{2}}$-Water spray & 27.01 & 27.06 & 27.50 & 27.50 & 27.77 & 28.01 \\
\hline $\mathbf{T}_{\mathbf{3}}$-Governemnt grade $\mathbf{2}$ & 30.56 & 31.85 & 36.04 & 37.18 & 38.92 & 39.12 \\
\hline $\mathbf{T}_{\mathbf{4}}$-Fe Gluconate & 36.24 & 40.78 & 41.04 & 41.98 & 42.35 & 43.79 \\
\hline $\mathbf{T}_{\mathbf{5}}$ - Fe EDTA & 35.77 & 36.23 & 36.41 & 39.06 & 39.88 & 40.15 \\
\hline Mean & $\mathbf{3 0 . 6 0}$ & $\mathbf{3 1 . 8 7}$ & $\mathbf{3 2 . 8 9}$ & $\mathbf{3 3 . 8 4}$ & $\mathbf{3 4 . 4 8}$ & $\mathbf{3 4 . 9 1}$ \\
\hline
\end{tabular}

Table.7 Effect of foliar feeding of gluconate and EDTA chelated plant nutrient on Mn concentration of Bt cotton in pot culture experiment

\begin{tabular}{|l|c|c|c|c|c|c|}
\hline \multirow{2}{*}{ Treatment } & \multicolumn{7}{|c|}{ Mn concentration } \\
\cline { 2 - 7 } & $\mathbf{3}$ hrs. & $\mathbf{6}$ hrs. & $\mathbf{1 2}$ hrs. & $\mathbf{2 4}$ hrs. & $\mathbf{3 6}$ hrs. & $\mathbf{4 8}$ hrs. \\
\hline $\mathbf{T}_{\mathbf{1}}$-Control & 1.99 & 1.99 & 1.99 & 2.00 & 2.00 & 2.01 \\
\hline $\mathbf{T}_{\mathbf{2}}$-Water spray & 2.16 & 2.16 & 2.17 & 2.18 & 2.18 & 2.21 \\
\hline $\mathbf{T}_{\mathbf{3}}$-Governemnt grade 2 & 3.56 & 3.62 & 4.18 & 4.20 & 4.21 & 4.21 \\
\hline $\mathbf{T}_{\mathbf{4}}$ - MnGluconate & 4.19 & 4.23 & 4.24 & 4.25 & 4.25 & 4.27 \\
\hline $\mathbf{T}_{\mathbf{5}}$-Mn EDTA & 4.10 & 4.18 & 4.21 & 4.21 & 4.22 & 4.23 \\
\hline Mean & $\mathbf{3 . 2 0}$ & $\mathbf{3 . 2 4}$ & $\mathbf{3 . 3 6}$ & $\mathbf{3 . 3 7}$ & $\mathbf{3 . 3 7}$ & $\mathbf{3 . 3 9}$ \\
\hline
\end{tabular}

Table.8 Effect of foliar feeding of gluconate and EDTA chelated plant nutrient on $\mathrm{Cu}$ concentration of Bt cotton in pot culture experiment

\begin{tabular}{|l|c|c|c|c|c|c|}
\hline \multirow{2}{*}{ Treatment } & \multicolumn{7}{|c|}{ Cu concentration } \\
\cline { 2 - 7 } & $\mathbf{3}$ hrs. & $\mathbf{6}$ hrs. & $\mathbf{1 2}$ hrs. & $\mathbf{2 4}$ hrs. & $\mathbf{3 6}$ hrs. & $\mathbf{4 8}$ hrs. \\
\hline $\mathbf{T}_{\mathbf{1}}$-Control & 2.56 & 2.56 & 2.56 & 2.57 & 2.57 & 2.58 \\
\hline $\mathbf{T}_{\mathbf{2}}$-Water spray & 2.75 & 2.75 & 2.76 & 2.77 & 2.77 & 2.77 \\
\hline $\mathbf{T}_{\mathbf{3}}$-Governemnt grade 2 & 3.05 & 3.08 & 3.15 & 3.16 & 3.16 & 3.18 \\
\hline $\mathbf{T}_{\mathbf{4}}$ - Cu Gluconate & 3.79 & 3.85 & 3.86 & 3.88 & 3.87 & 3.90 \\
\hline $\mathbf{T}_{\mathbf{5}}$ Cu EDTA & 3.79 & 3.80 & 3.80 & 3.80 & 3.82 & 3.83 \\
\hline Mean & $\mathbf{3 . 1 9}$ & $\mathbf{3 . 2 1}$ & $\mathbf{3 . 2 3}$ & $\mathbf{3 . 2 4}$ & $\mathbf{3 . 2 4}$ & $\mathbf{3 . 2 5}$ \\
\hline
\end{tabular}


Treatment $\mathrm{T}_{4}$ (Mn gluconate) ranged varied from 4.19 to 4.27 whereas $\mathrm{T}_{5}$ (Mn EDTA) varied from 4.10 to 4.23 and $\mathrm{T}_{3}$ (Government grade 2) varied form (3.56 to 4.21). The rate and amount of absorption of Mn was highest in interval of 3 to 6 hours in treatment $\mathrm{T}_{4}(\mathrm{Mn}$ gluconate) and $\mathrm{T}_{5}$ (Mn EDTA) and from 6 to 12 hours in treatment $T_{3}$ (Government grade 2). In case of $\mathrm{T}_{1}$ (control) and $\mathrm{T}_{2}$ (water spray) lowest concentration was recorded in these treatments as in $\mathrm{T}_{1}$ (1.99 to 2.01$)$ and $\mathrm{T}_{2}(2.16$ to $2.21 \mathrm{mg}$ $\left.\mathrm{kg}^{-1}\right)$, respectively.

\section{Cu concentration}

It was clearly recorded in the Table 8 that, very low absorption of copper was recorded in each of $\mathrm{T}_{1}$ and $\mathrm{T}_{2}$ treatments. The maximum copper concentration was found in treatment $\mathrm{T}_{4}(\mathrm{Cu}$ gluconate) (3.79 to 3.90$)$ followed by $\mathrm{T}_{5}(\mathrm{Cu}$ EDTA) (3.79 to 3.83).

From the data it could be inferred that treatment $\mathrm{T}_{4}(\mathrm{Cu}$ gluconate) showed the greater amount of copper and maximum absorption between 3 to 6 hours after spraying.

Conclusion is as follows:

Use of $\mathrm{Zn}$ gluconate had maximum absorption in case of $\mathrm{Zn}$ concentration and was maximum at 3-6 hours. Iron concentration was more at 6 hours due to application of Fe gluconate $\left(\mathrm{T}_{4}\right)$, followed by Fe EDTA $\left(\mathrm{T}_{5}\right)$ as compared to control $\left(\mathrm{T}_{1}\right)$, while the application of manganese gluconate had maximum absorption of manganese by $\mathrm{Bt}$ cotton plant. Application of $\mathrm{Cu}$ gluconate was absorbed at higher rate after 6 hours of spray and resulted in more amount of concentration comparing to control, water spray and Government grade 2. In pot culture experiment, it is concluded that foliar feeding of $\mathrm{Zn}$ gluconate showed maximum plant height, number of leaves, leaf area and dry weight plant $^{-1}$ as well as improves the yield parameters like number of bolls, weight of bolls and yield over all the treatments.

The foliar feeding $\mathrm{Ca}, \mathrm{Mg}, \mathrm{Zn}, \mathrm{Fe}, \mathrm{Mn}$ and $\mathrm{Cu}$ with gluconate found to be effective in absorption of respective nutrients within 3 to 6 hours of spraying.

\section{References}

Anonymous, (2010). Cotton advisory board, Cotton Corporation of India 2010

Das, D.K., Karak, T., and D. Maiti (2004). Effect of foliar application of different sources of $\mathrm{Zn}$ on the changes in $\mathrm{Zn}$ content, uptake and yield of rice (Oryza sativa L.). Ann. Agric. Res. New series, 25(2): 253-256.

Gangadhar, G.A., H.M. Manjunathaiah and T. Satyanarayana (1992).Effect of micronutrients on the yield and uptake of sunflower. J. Indian Soc. Soil Sci., 40: 591-593.

Jat, J.R. and R.K. Mehra (2007). Effect of sulphur and zinc on yield, micronutrient content in and uptake by mustard on haplustepts. J. Indian Soc. Soil Sci., 55(2): 190-195.

Sarkar, S. and N.C. Aery (1990).Effect of zinc on growth of soybean. Indian J. Plant Physiol., $\quad 33(3)$ : 239241.www.cotcorp.gov.in.

Panse, V.G. and P.V. Sukhatme (1988). Statistical methods of Agricultural Workers, ICAR Publication, New Delhi.

\section{How to cite this article:}

Gourkhede, P.H., V.D. Patil and Pathrikar, D.T. 2019. Response of Foliar Feeding of Gluconate and EDTA Chelated Plant Nutrients on Growth, Yield and Absorption of Nutrients by Leaves in Bt-Cotton under Rainfed Condition. Int.J.Curr.Microbiol.App.Sci. 8(04): 946-953. doi: https://doi.org/10.20546/ijcmas.2019.804.109 